\title{
Cobertura de solo modifica a performance de coentro
}

\author{
Mulching modifies coriander yield \\ El mantillo modifica el rendimiento del cilantro
}

Recebido: 01/10/2020 | Revisado: 14/10/2020 | Aceito: 08/04/2021 | Publicado: 09/04/2021

Letícia Junnyane Costa Pamplona
ORCID: https://orcid.org/0000-0003-2514-2817
Instituto Federal de Educação, Ciência e Tecnologia do Rio Grande do Norte, Brasil
E-mail: leticiajunnyane02@ gmail.com
Luiz Leonardo Ferreira
ORCID: https://orcid.org/0000-0001-5444-8503
Centro Universitário de Mineiros, Brasil
E-mail: leoagrozoo@ hotmail.com
Felipe Bruno Morais Dantas da Silva
ORCID: https://orcid.org/0000-0002-0985-9511
E-mail: felipebrunomorais@gmail.com
Carlos Daniel Oliveira Morais
Instituto Federal de Educação, Ciência e Tecnologia Ris
ORCID: https://orcid.org/0000-0002-1549-7211
E-mail: daniel20152623@gmail.com
Renato Dantas Alencar
Instituto Federal de Educação, Ciência e Tecnologia do Rio Grande dorte, Brasil
ORCID: https://orcid.org/0000-0002-9039-3594
E-mail: alencarenato@ dorte, Brasil
Instituto Federal de Educação, Ciência e Tecnologia do Rio Grande do
Vania Christina Nascimento Porto
ORCID: https://orcid.org/0000-0002-0352-0162
E-mail: vania@ @ufersa.edu.br
Camila de Souza Alves
Instituto Federal de Educação, Ciência e Tecnologia do Rio Grande do Norte, Brasil
E-mail: souzacamila889@gmail.com

\section{Resumo}

No Semiárido brasileiro, a água é um aspecto restringente tanto para o consumo familiar e dos animais, como para o cultivo de alimentos. A cobertura do solo com restos vegetais pode diminuir a evaporação da água disponibilizada às plantas. Diante do exposto, objetivou-se com o trabalho, determinar uma cobertura morta de solo que atenda as exigências da cultura do coentro (Coriandrum sativum) e melhore a performance produtiva desta apiácea. Os tratamentos constaram de quatro coberturas mortas, utilizando as espécies: Leucena (Leucaena leucocephala), Nim (Azadirachta indica), Flor-de-seda (Calotropis procera), Carnaúba (Copernicia prunifera), e uma testemunha (sem cobertura morta). Analisou-se a influência das coberturas no coentro aos 10, 20 e 30 dias após a semeadura. Os diferentes tipos de cobertura do solo, associado as épocas de avaliação, alteraram o comportamento da cultura do coentro. Recomenda-se para a cobertura do coentro a utilização de palhada de Leucena) para altos rendimentos. Demais trabalhos que envolvam a temática de cobertura morta para o semiárido devem ser desenvolvidos, para melhor utilização do recurso hidrológico desta região, haja vista a sua escassez. Perspectivas como outras espécies para cobertura morta, densidade de cobertura e nível de decomposição da palhada são atributos que podem ser analisados e vir a somar a este estudo.

Palavras-chave: Apiaceae; Cobertura morta; Coriandrum sativum; Olerícolas.

\begin{abstract}
In the Brazilian semiarid region, water is a restrictive aspect both for family and animal consumption, and for growing food. Covering the soil with vegetable debris can reduce the evaporation of water made available to plants. In view of the above, the objective of the work was to determine a mulch of soil that meets the requirements of the culture of coriander (Coriandrum sativum) and improves the productive performance of this apiaceae. The treatments consisted of four dead coverings, using the species: Leucena (Leucaena leucocephala), Neem (Azadirachta indica), Silk-flower (Calotropis procera), Carnaúba (Copernicia prunifera), and a witness (without dead cover). The influence of coverages on coriander at 10,20 and 30 days after sowing was analyzed. The different types of soil cover, associated with the evaluation periods, changed the behavior of the coriander culture. It is recommended to cover coriander the
\end{abstract}


use of Leucena straw) for high yields. Other works involving the theme of mulch for the semiarid region must be developed, to better use the hydrological resource of this region, given its scarcity. Perspectives such as other species for mulch, cover density and straw decomposition level are attributes that can be analyzed and added to this study.

Keywords: Apiaceae; Mulch; Coriandrum sativum; Oleraceous.

\section{Resumen}

En la región semiárida brasileña, el agua es un aspecto restrictivo tanto para el consumo familiar y animal, como para el cultivo de alimentos. Cubrir el suelo con restos vegetales puede reducir la evaporación del agua disponible para las plantas. En vista de lo anterior, el objetivo del trabajo fue determinar un mantillo de suelo que cumpla con los requisitos del cultivo de cilantro (Coriandrum sativum) y mejore el comportamiento productivo de esta apiácea. Los tratamientos consistieron en cuatro coberturas muertas, utilizando las especies: Leucena (Leucaena leucocephala), Neem (Azadirachta indica), Flor de seda (Calotropis procera), Carnaúba (Copernicia prunifera) y un testigo (sin cobertura muerta). Se analizó la influencia de las coberturas sobre el cilantro a los 10, 20 y 30 días después de la siembra. Los diferentes tipos de cobertura del suelo, asociados a los períodos de evaluación, cambiaron el comportamiento del cultivo de cilantro. Se recomienda tapar el cilantro con el uso de paja de Leucena) para altos rendimientos. Se deben desarrollar otros trabajos que involucren el tema del acolchado para la región semiárida, para aprovechar mejor el recurso hidrológico de esta región, dada su escasez. Perspectivas como otras especies para mantillo, densidad de cobertura y nivel de descomposición de la paja son atributos que se pueden analizar y agregar a este estudio.

Palabras clave: Apiáceas; Mantillo; Coriandrum sativum; Oleráceas.

\section{Introdução}

O coentro, que pertence à família Apiaceae, é uma hortaliça herbácea anual pouco estudada, apesar de ser considerada no ramo alimentício, rica em vitaminas e sais minerais, e com capacidade de produzir grandes quantidades de sua planta por unidade de área. No Brasil, as condições edafoclimáticas permitem o cultivo de diversas variedades desse vegetal durante o ano todo, com a utilização de irrigação. Essa olerícola é consumida em quase todo o globo, diante de suas características nutritivas na culinária, alto teor de vitaminas, propriedades medicinais, notável valor e relevância socioeconômica global (Silva et al., 2013).

A produção orgânica de hortaliças vem aumentando em área e em produção, devido principalmente à demanda por produtos de base ecológica, o que demonstra a preocupação do consumidor brasileiro com a qualidade nutricional e com métodos de produção que respeitam o meio ambiente e tenham uma produção sustentável.

Algumas técnicas de cultivo têm sido utilizadas em hortaliças com a finalidade de obter melhor qualidade e produtividade, além da precocidade, como a cobertura do solo associada com a proteção de plantas (Cavalcante Neto et al., 2010). A decisão do material utilizado nesse processo, deve visualizar, principalmente, uma redução de custos na produção, tornando-se assim mais viável fazer uso dos materiais presentes na própria propriedade e que apresente outras aplicações de uso.

No Semiárido brasileiro, a água é um aspecto restringente tanto para o consumo familiar, para os animais de criação, bem como, no cultivo de alimentos. Nesta região, os sistemas de exploração agropecuários sustentam-se em estabilidade incerta devido a baixos índices pluviométricos e chuvas irregulares (Brito et al. 2012). Nessa perspectiva, a utilização de métodos de manejo para agregar a eficiência do uso da água e, por conseguinte, minimizar os déficits hídricos pelas culturas devem ser adotadas para rendimentos satisfatórios. Dentre esses métodos, sobressai-se a aplicação da cobertura morta no solo (Murga-Orrillo et al., 2016).

A cobertura do solo com restos vegetais é utilizada objetivando diminuir a evaporação da água disponibilizada às plantas, proporcionando depleção nos quantitativos de sais na superfície do solo (Peres et al., 2010). Uma cobertura com ótimo potencial de uso é a flor-de-seda (Calotropis procera), que tem sua incidência durante todo ano, consequência da sua capacidade de se manter verde e sua rebrota ocorrer no período da ausência de chuvas. Com produtividade média de 1,0 t/ha/corte/ano de fitomassa seca, permite até três cortes anuais, com teor de nitrogênio de 22,6 g/kg na fitomassa seca e relação carbono nitrogênio de 20:1 (Linhares et al., 2011). 
Outra cobertura que obtém interessante destaque é a palha de carnaúba triturada (Copernicia prunifera), que tem sido bastante utilizada pelos agricultores nessa finalidade, principalmente para facilitar a germinação e emergência do coentro, pois a mesma garante a manutenção da umidade do solo por um período mais longo, além de servir no controle das plantas daninhas (Linhares et al., 2014).

O Nim (Azadirachta indica), que pertence à família Meliaceae, vem sendo bastante disseminado no Semiárido. Isto deve-se ao seu rápido crescimento e utilização de suas folhas para o combate de pragas agrícolas, por suas particularidades medicinais e inseticidas, bem como resistência e dureza de sua madeira, o que garante grande prolongação de uso. Além disso, sua capacidade de rebrota permite vários cortes ao longo de décadas de cultivo (Okmar, 2012).

Além do fácil acesso na região de semiárido, a Leucena (Leucaena leucocephala) é mais uma cultura cujo uso de biomassa verde triturada como cobertura acarretam efeitos positivos sobre o desenvolvimento inicial de hortaliças, sendo o principal destes, o vigor das plantas, afetados diretamente pelo potencial da nutrição nitrogenada da mesma (Favarato, 2017).

Diante do exposto, objetivou-se com o trabalho, determinar uma cobertura morta de solo que atenda as exigências da cultura do coentro e melhore a performance produtiva desta apiácea.

\section{Metodologia}

O trabalho foi desenvolvido no viveiro de mudas do Instituto Federal de Educação, Ciência e Tecnologia do Rio Grande do Norte - Campus Apodi, no município de Apodi, na Chapada Apodi (-562’ S, $-37^{\circ} 0$ ’ W e altitude de 116,8 metros), Rio Grande do Norte, Brasil. O clima da região, de acordo com a classificação de Köppen e Geiger (1936), é definido como BSh, isto é, clima semiárido, com precipitação anual total média compreendida entre 380 e $760 \mathrm{~mm}$, com temperatura anual média de $18^{\circ} \mathrm{C}$. O solo da região é classificado como Argissolo (EMBRAPA, 2018).

O experimento foi implantado em canteiros de alvenaria, com 5,3 metros de comprimento, 1,3 metros de largura e 0,2 metros de profundidade. O delineamento experimental foi em blocos casualizados, com 4 repetições e 15 tratamentos. Os tratamentos constaram de 5 coberturas mortas utilizando as espécies Leucena (Leucaena leucocephala), Nim (Azadirachta indica A. Juss), Flor-de-seda (Calatropis Procera), Carnaúba (Copernicia prunifera) e Testemunha (sem cobertura morta), e analisadas a influência destas no coentro aos 10, 20 e 30 dias após a semeadura, seguindo a metodologia de Resende et al. (2005). A descrição dos tratamentos se encontra na Tabela 1. 
Tabela 1. Descrição dos tratamentos utilizados na performance do coentro submetido a diferentes tipos de cobertura morta e avaliado em diferentes épocas pós semeadura

\begin{tabular}{|c|c|}
\hline Tipo de cobertura morta do solo e avaliação após a semeadura & Sigla \\
\hline Palha de Carnaúba e avaliação 10 dias após a semeadura & $1^{\mathrm{a} C}$ Carnauba \\
\hline Palha de Flor-de-seda e avaliação 10 dias após a semeadura & $1^{\text {a }}$ Flordeseda \\
\hline Palha de Leucena e avaliação 10 dias após a semeadura & $1^{\mathrm{a} L e u c e n a}$ \\
\hline Palha de Nim e avaliação 10 dias após a semeadura & $1^{\mathrm{a}} \mathrm{Nim}$ \\
\hline Sem cobertura e avaliação 10 dias após a semeadura & $1{ }^{a}$ Semcobertura \\
\hline Palha de Carnaúba e avaliação 20 dias após a semeadura & $2^{\mathrm{a} C a r n a u b a}$ \\
\hline Palha de Flor-de-seda e avaliação 20 dias após a semeadura & $2^{\text {a }}$ Flordeseda \\
\hline Palha de Leucena e avaliação 20 dias após a semeadura & $2^{\mathrm{a} L e u c e n a}$ \\
\hline Palha de Nim e avaliação 20 dias após a semeadura & $2^{\mathrm{a}} \mathrm{Nim}$ \\
\hline Sem cobertura e avaliação 20 dias após a semeadura & $2^{\text {a Semcobertura }}$ \\
\hline Palha de Carnaúba e avaliação 30 dias após a semeadura & $3^{\mathrm{a} C a r n a u b a}$ \\
\hline Palha de Flor-de-seda e avaliação 30 dias após a semeadura & $3^{\text {a}}$ Flordeseda \\
\hline Palha de Leucena e avaliação 30 dias após a semeadura & $3^{\mathrm{a} L e u c e n a}$ \\
\hline Palha de Nim e avaliação 30 dias após a semeadura & $3^{\mathrm{a}} \mathrm{Nim}$ \\
\hline Sem cobertura e avaliação 30 dias após a semeadura & $3^{\text {a Semcobertura }}$ \\
\hline
\end{tabular}

Fonte: Autores.

As coberturas mortas foram compostas por folhas e ramos com diâmetros de até $1 \mathrm{~cm}$, triturados e secos das espécies Leucena, Nim, Flor de seda, Carnaúba (Tavella et al., 2010). O semeio foi efetivado em sulcos longitudinais com distância de $20 \mathrm{~cm}$ entre linhas e profundidade de $1 \mathrm{~cm}$. Durante o experimento, capinas manuais periódicas foram realizadas. A irrigação foi efetuada duas vezes ao dia, por micro aspersão, até a capacidade de campo. As coberturas mortas foram postas nos canteiros quando a plântula ainda estava com $5 \mathrm{~cm}$ de altura, aproximadamente 15 dias após plantio. Foram colocadas camadas com média de $4 \mathrm{~cm}$ de altura da cobertura referente ao espaço de tratamento sendo aproximadamente $4 \mathrm{~cm}^{3} / \mathrm{m}^{2} \mathrm{de} \mathrm{material} \mathrm{por}$ tratamento, e os mesmos permaneceram durante todo o restante do ciclo cultural.

Os parâmetros avaliados foram: altura de plantas (ALT), determinada em uma amostra de cinco plantas escolhidas aleatoriamente na parcela útil, medindo-as com o auxílio de réguas desde o colo até a extremidade das folhas mais altas, expressa em centímetros; Número de hastes por planta (NUH), obtido através da contagem ordinária; Massa fresca da parte aérea (MFA), obtida utilizando-se o peso da massa fresca das plantas da área útil da parcela; Massa seca da parte aérea (MAS), determinada em estufa com circulação forçada de ar a $70^{\circ} \mathrm{C}$ até atingir peso constante; Número de molhos/m² (obtido em molhos de 100 (cem) gramas de plantas, constituídos de hastes e folhas); Massa fresca da raiz (MFR), seguindo o mesmo método da massa fresca da parte aérea e massa seca da raiz (MSR), determinada da mesma forma da anterior.

Os dados foram submetidos as pressuposições do modelo estatístico, verificando-se a normalidade (Shapiro e Wilk, 1965) e homogeneidade das variâncias (Steel et al., 1997). Após, realizou-se a análise de variância multivariada com significância baseada no Teste de Hotelling-Lawley. Depois, utilizou-se o critério de Singh (1981) para quantificar a contribuição relativa dos caracteres na divergência entre os tratamentos. Posteriormente as variáveis foram submetidas as correlações de Pearson com intuito de compreender a tendência de associação, sendo sua significância baseada a 5\% de probabilidade pelo teste t. Posteriormente, empregou-se o método dos componentes principais biplot, onde possibilitou 
visualizar a variabilidade geral do experimento e as tendências multivariadas. Após procedeu-se a dissimilaridade pelo algoritmo de Mahalanobis, onde ponderou-se a matriz dos resíduos, construindo-se o dendrograma Heatmap com agrupamento das médias por UPGMA e otimizado pelo método de Tocher (RAO, 1952). O Multi-trait stability Index foi proposto de acordo com Olivoto et al. (2019). As análises foram realizadas no programa estatísticos R Core Team (2019).

\section{Resultados e Discussão}

Os diferentes tipos de cobertura do solo, associado as épocas de avaliação, alteraram o comportamento da cultura do coentro. Através das análises multivariadas pode-se comprovar a influência dos tratamentos sobre o comportamento do coentro, onde seus caracteres foram mensurados quanto ao seu peso na distinção dos tratamentos e correlacionados entre si. Correlações entre os caracteres e tratamentos foram reportadas, além do agrupamento dos tratamentos e indicação por multicaráter revelado.

A análise de variância multivariada, baseada no Teste de Holling-Lawley, revelou diferença significativa $(\mathrm{p}<0,01)$ entre os tratamentos (Tabela 2). Essa informação reforça a hipótese de que as variáveis sofreram alterações em respostas aos distintos tratamentos. Poucos são as informações que validam trabalhos com coentro em análise de variância multivariada, como em Silva et al. (2018), que avaliaram parâmetros de crescimento e eficiência no uso da água pela cultura do coentro. Contradizendo a significância encontrada neste trabalho, Cavalcante Neto et al. (2010), observaram que as variáveis altura de planta, número de folhas e comprimento da raiz do coentro, não variaram suas médias em função da cobertura morta.

Tabela 2. Análise de variância multivariada aplicada aos efeitos dos tratamentos para os caracteres de coentro, com significância baseada no Teste de Hotelling-Lawley.

\begin{tabular}{lllllll}
\hline Df & Gl & approx & F num & Df den & Df & $\operatorname{Pr}(>\mathrm{F})$ \\
\hline Tratamentos & 14 & 205.745 & 83.552 & 98 & 1967 & $<2 \mathrm{e}-16^{* *}$ \\
Blocos & 4 & 0.10963 & 11.191 & 28 & 1112 & 0.3056 \\
Resíduo & 281 & & & & & \\
\hline
\end{tabular}

*** significativo a $0.1 \%$ de probabilidade pelo teste Hotelling-Lawley. Genótipos da alface $\mathrm{x}$ ambiência x fertilizante. Fonte: Autores.

A análise de contribuição dos caracteres relatou que a característica de maior peso na divergência dos tratamentos foi a altura de planta (75\%), seguida do comprimento radicular (19\%), sendo estas duas, responsáveis por 94\% da variação dos tratamentos (Figura 1). As demais características pouco foram expressivas na distinção dos tratamentos. Fernandes et al. (2016), verificaram que o número de molho, matéria seca e fresca, foram superiores quando no sistema de produção com a presença da cobertura morta, destacando-se o aumento na produtividade, onde estas foram as variáveis de maior importância na distinção dos tratamentos. 
Figura 1. Contribuição relativa dos caracteres da cultura do coentro submetido a diferentes coberturas de solo.

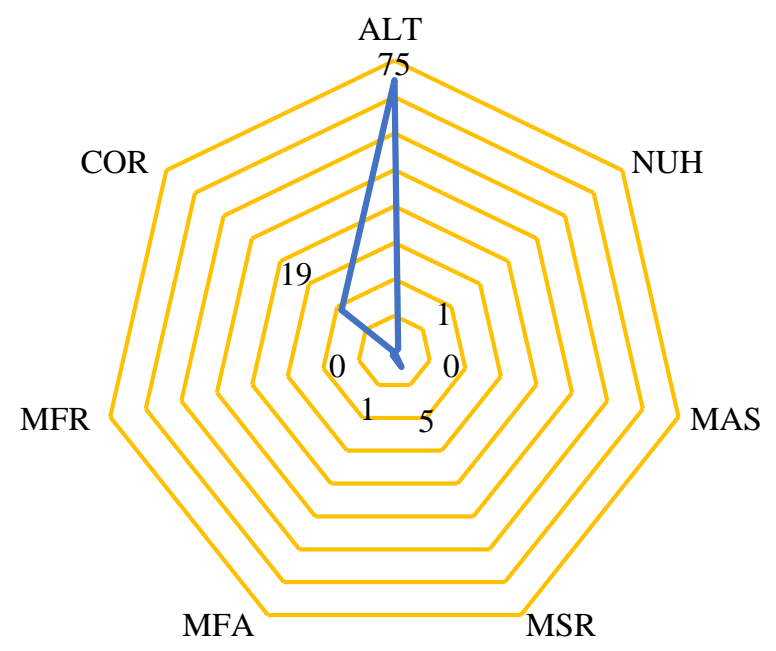

Fonte: Autores.

As correlações fenotípicas entre os caracteres apresentaram 11 pares significativos e positivos, correspondendo a $52,38 \%$ do conjunto de dados. Os pares de maior carga correlativa foram verificados na massa fresca aérea com a massa aérea seca (MFAxMAS: 0.99***) e com a massa fresca da raiz (MFAxMFR: 0.99***) (Figura 2). Cabe lembrar que as correlações positivas determinam acréscimos simultâneos entre os caracteres, desta forma, podemos melhorar a performance do vegetal por efeitos paralelos a estes, como as variáveis acessórios. Os dados apresentados mostram diferenças na magnitude e direção dos valores de correlação, com correlações positivas e significativas na cultura do coentro, como reportado por Tunes et al. (2011), Torres et al. (2012) e Pereira et al. (2015), que também encontraram correlações significativas no potencial fisiológico de sementes de coentro. Para Magi e Mendes (2019) a matéria fresca da parte aérea do coentro é um dos principais objetivos dos produtores, e o uso da cobertura morta, se mostrou uma alternativa interessante para o cultivo desta olerícola, reforçando a importância do uso de técnicas de manejo que propiciem a proteção e manutenção da umidade do solo em sistema orgânico de produção, como já observados em outros trabalhos realizados. 
Figura 2. Correlação fenotípica aplicado aos caracteres da cultura do coentro submetido a diferentes coberturas de solo.

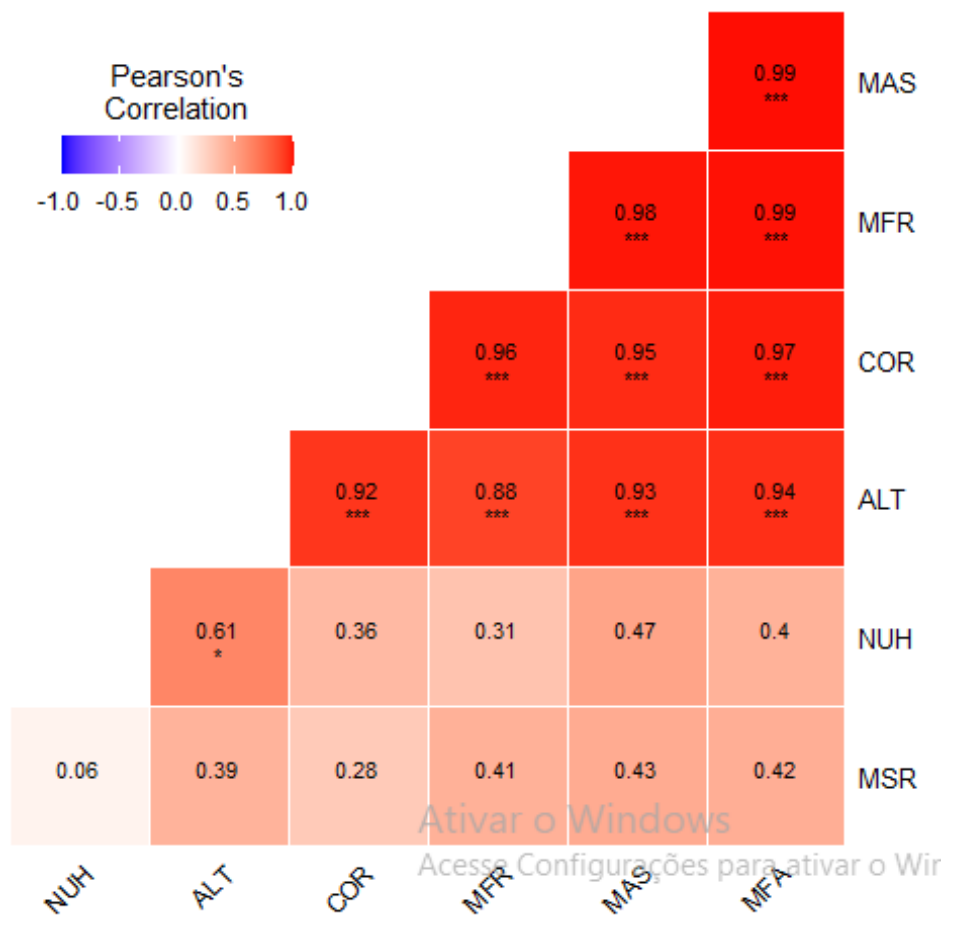

Fonte: Autores.

A análise de componentes principais explicou 88,85\% da variação total dos dados. As variáveis ALT, MAS, MFR, MFA e COR apresentaram maior relevância para o desenvolvimento da cultura (Figura 3B). Conforme critérios de seleção dos componentes, esta pesquisa adotou a retenção dos componentes que explicaram mais de $70 \%$ da variância, conforme sugerido por Kaiser (1960). As coberturas que possuem maior influência para o desenvolvimento da cultura do coentro foram as da primeira avaliação (Figura 3C). As coberturas na $3^{\text {a }}$ avaliação, com exceção da flor-de-seca, apresentaram afinidade com as características de ALT, COR, MFA e MFR (Figura 3A). Bertini et al. (2010) através dos componentes principais reduziram as dez características em dois componentes principais, que explicaram 81,3\% da variância total. Os dois primeiros componentes principais permitiram explicar 59,0\% da variância contida nas variáveis originais (Tobar-Tosse et al., 2015). A análise de componentes principais determina as variáveis mais importantes e contribui no entendimento de seu inter-relacionamento (Ramos e Ribeiro, 2019). 
Figura 3: Análise de componentes principais aplicado a cultura do coentro submetido a diferentes coberturas de solo.

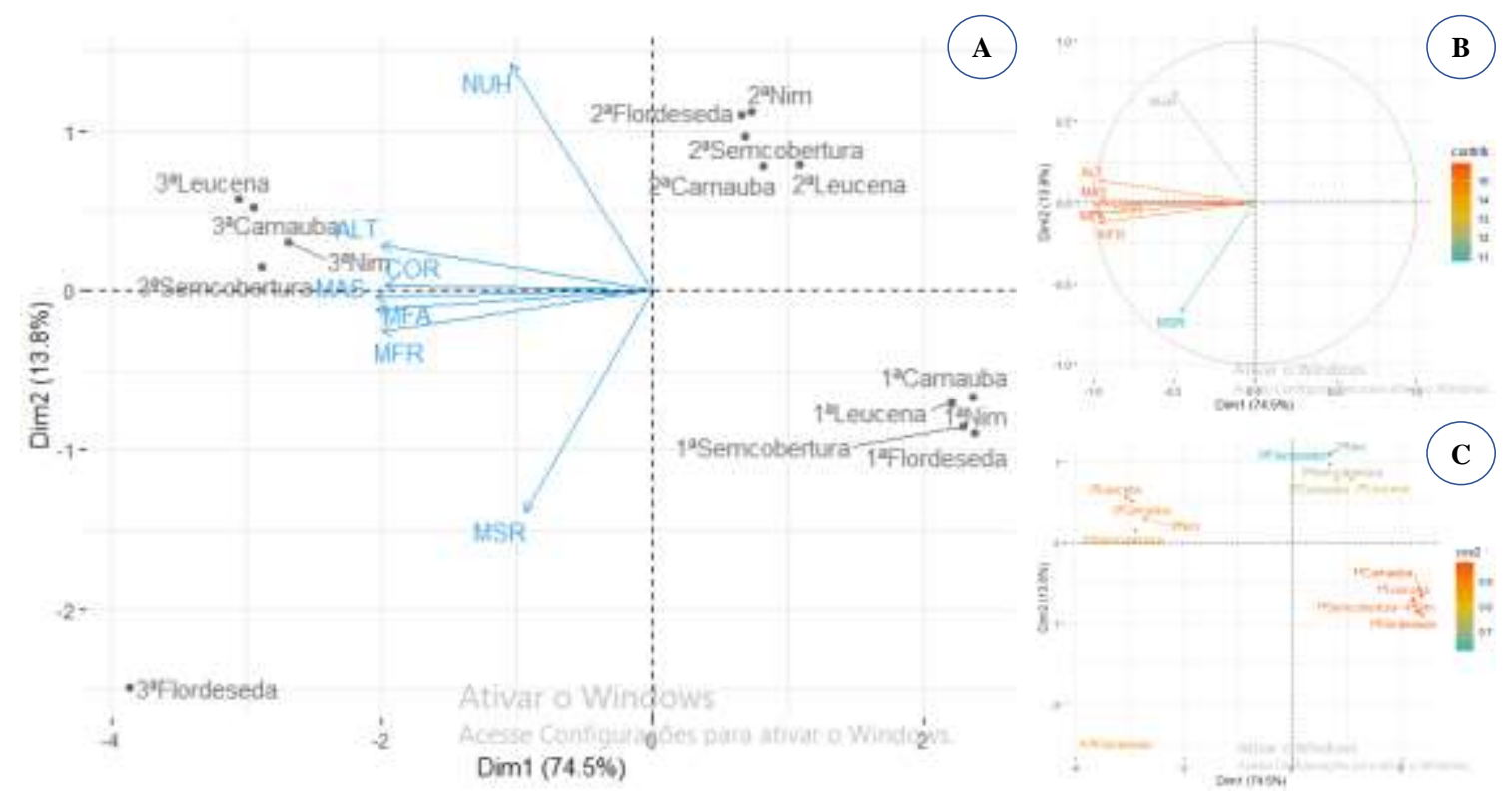

Fonte: Autores.

Analisando o Agrupamento Hierárquico da Distância Média (UPGMA) obteve-se o dendrograma de ponto de corte 3.06 e coeficiente de correlação cofenético igual a 95\%, dividido em 3 clusters. O cluster I foi representado pelas coberturas analisadas na primeira e na segunda avaliação, e que apresentaram as menores médias de crescimento dos caracteres analisados. O cluster II, teve como representante único, a cobertura de flor-de-seda na terceira avaliação, e se caracterizou por valores intermediários dos caracteres, com exceção MSR, que foi bem elevada. O cluster III, assim como o II apresentou caracteres um pouco acima da média, porém com a MSR baixa (Figura 4A). Com a análise de agrupamento hierárquica na cultura do coentro, Ramos e Ribeiro (2019) e Acedo-Félix et al. (2009) também poderão descrever os tratamentos de melhor performance.

De acordo com a multitrait stability index, a cultura do coentro apresentou alta performance na terceira avaliação, utilizando como cobertura a palhada de Leucena, seguido da ausência de palhada, também na terceira avaliação. A palha de carnaúba apresentou-se próximo do ponto de corte, podendo em outros trabalhos serem novamente testadas (Figura 4B). O uso da cobertura morta proporciona ganho produtivo para a maioria das características agronômicas avaliadas em cultivo de coentro orgânico, sendo então, recomendada esta técnica (Fernandes et al., 2016). O plantio direto com palhada de resteva morta proporciona desempenho agronômico do coentro, em cultivo orgânico, semelhante ao preparo convencional do solo, ambos superiores ao plantio direto com cobertura viva de amendoim forrageiro ou plantas espontâneas (Tavella et al., 2010). 
Figura 4. Dendrograma Heatmap, com agrupamento UPGMA e grupos otimizados por Tocher (A) e seleção para o multitrait stability index considerando uma intensidade de seleção de $15 \%$, da cultura do coentro submetido a diferentes coberturas de solo.
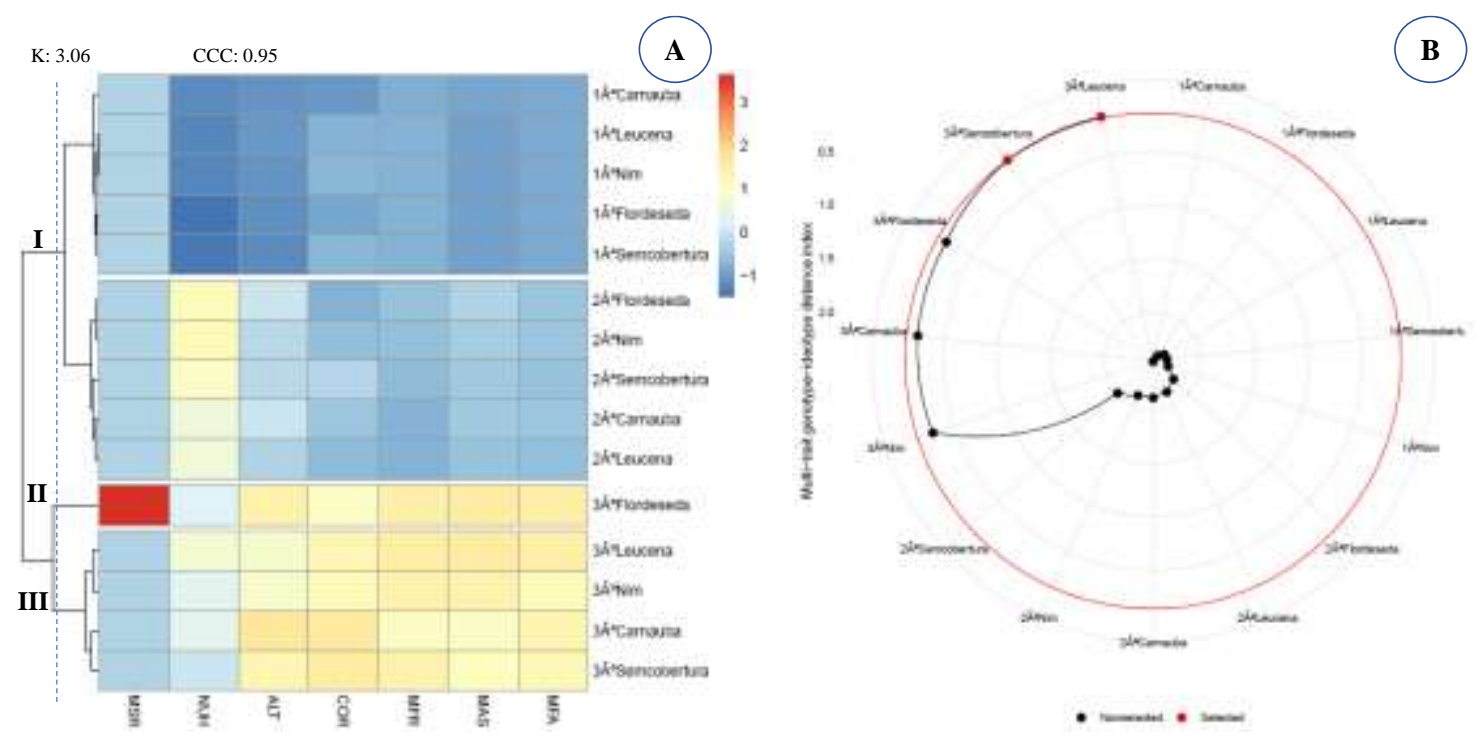

Fonte: Autores.

Dos Fernandes et al. (2016), verificaram que as variáveis número de molhos, matéria seca, matéria fresca e produtividade, na cultura do coentro, foram significativamente elevadas quando a cobertura morta foi implementada no sistema de produção, enfatizando-se o acréscimo na produtividade. O emprego da cobertura morta propicia benefícios produtivos para a maior parte das características agronômicas avaliadas no cultivo orgânico do coentro sendo, portanto, sugerida essa técnica. Tavella et al. (2010) relaciona esse elevado acréscimo na produção ao se empregar cobertura morta a princípios ecológicos, dentre eles, de acordo com Souza et al. (2011) sobressai-se a maior conservação da água no solo, pela alteração na relação entre água e solo, minimizando o percentual de evapotranspiração das culturas, sobretudo nos estágios nos quais o seu dossel não sombreou o solo por inteiro.

\section{Considerações Finais}

Para altos rendimentos na cultura do coentro (Coriandrum sativum), recomenda-se a cobertura do solo com palhada de Leucena (Leucaena leucocephala).

Demais trabalhos que envolvam a temática de cobertura morta para o semiárido devem ser desenvolvidos, para melhor utilização do recurso hidrológico desta região, haja vista a sua escassez. Perspectivas como outras espécies para cobertura morta, densidade de cobertura e nível de decomposição da palhada são atributos que podem ser analisados e vir a somar neste estudo.

\section{Referências}

Acedo-Félix, E.; Núñez-Hernández, Y.; Pérez-Morales, R.; Iñiguez-Palomares, C. M. \& Castillón-Campaña, L. (2009). Caracterización polifásica de Salmonella spp. aislada de campos agrícolas de melón (Cucumis melo) y cilantro (Coriandrum sativum). Interciencia, 34(6), 419-423.

Bertini, C. H. D. M.; Pinheiro, E. A. R.; Nóbrega, G. N. \& Duarte, J. M. D. L. (2010). Desempenho agronômico e divergência genética de genótipos de coentro. Revista Ciência Agronômica, 41(3), 409-416.

Brito, L. T. L.; Cavalcanti, N. B.; Silva, A. S. \& Pereira, L. A. (2012) Produtividade da água de chuva em culturas de subsistência no semiárido pernambucano. Engenharia Agrícola, 32(1), 102-109. 
Cavalcante Neto, J. G.; de Medeiros, D. C.; Marques, L. F.; de Sousa Nunes, G. H. \& do Vale, L. S. (2010). Cultivo do coentro com e sem cobertura do solo em diferentes espaçamentos. Revista Engenharia Ambiental, 7, 106-citation_lastpage.

Da silva, V. P. R.; Tavares, A. L. \& De sousa, I. F. (2013) Evapotranspiração e coeficientes de cultivo simples e dual do coentro. Hortic. Bras, 31(2).

Embrapa. (2018): Sistema brasileiro de classificação de solos. (5.ed.). Brasília 353p. 82-105.

Favarato, L. F.; de Souza, J. L.; Guarçoni, R. C. \& Pereira, V. A. P. A. (2017) Biomassa verde de plantas como adubo de cobertura em cultivo orgânico de repolho. Revista Brasileira De Agropecuária Sustentável, 7(3), 2017.

Fernandes, C. D. S.; Ferreira, L. L.; Silva, H. E. R. D.; Martins, A. F. \& Porto, V. C. N. (2016). A influência da cobertura morta no desempenho agronômico do coentro adubado com esterco bovino. Cadernos de Agroecologia, 10(3).

Kaiser, H. F. (1960) The application of electronic computers to factor analysis. Educational and Psychological Measurement. 20(1),141-151.

Köppen, W. \& Geiger, R. (1936) Handbuch der klimatologie. Gebrüder Borntraeger, Berlin.

Linhares, P. C. F.; Oliveira, J. D. D.; Pereira, M. F. S.; Fernandes, J. P. P. \& Dantas, R. D. P. (2014) Espaçamento para cultura do coentro adubado com palha de carnaúba nas condições de Mossoró, RN. Revista Verde de Agroecologia e Desenvolvimento Sustentável, 9(3), 1-6.

Linhares, P. C.; Silva, M. L. D.; Pereira, M. F. S; Bezerra, A. K. D. H. \& Paiva, A. C. C. (2011). Quantidades e tempos de decomposição da flor-de-seda no desempenho agronômico do rabanete. Revista Verde, v.6, n.1, p.168 - 173.

Maggi, C. F. \& MENDES, M. (2019). Uso de Diferentes Coberturas de Solo em Sistema de Policultivo de Alface, Rabanete e Coentro. Cadernos de Agroecologia, 14(1).

Murga-Orrillo, H.; Araújo, W. F.; Rodriguez, C. A.; Lozano, R. M. B.; Sakazaki, R. T. \& Vargas, A. R. P. (2016) Influência da cobertura morta na evapotranspiração, coeficiente de cultivo e eficiência de uso de água do milho cultivado em cerrado. Irriga, 21(2), 352.

Neto, J. G. C.; Medeiros, D. C.; Marques, L. F.; Nunes, G. H. S. \& Vale, L. S. (2010) Cultivo do coentro com e sem cobertura do solo em diferentes espaçamentos. Revista Engenharia Ambiental, v. 7, p. 106.

Olivoto, T.; Lúcio, A. D.; da Silva, J. A.; Sari, B. G. \& Diel, M. I. (2019). Mean Performance and Stability in Multi-Environment Trials II: Selection Based on Multiple Traits. Agronomy Journal, 111(6), 2961-2969.

Omkar, G. M. (2012). Neem, the wonder tree, under attack: A new major pest. Current Science. Bangalore, 102(7), 960-970.

Pereira, M. F. S., Torres, S. B., \& Linhares, P. C. F. (2015). Teste de envelhecimento acelerado para avaliação do potencial fisiológico em sementes de coentro. Semina: Ciências Agrárias, 36(2), 595-605.

Peres, J. G.; Souza, C. F. \& Lavorenti, N. A. (2010). Avaliação dos efeitos da cobertura de palha de cana-de-açúcar na umidade e na perda de água do solo. Engenharia Agrícola, 30(5), 875-886.

R Core Team. (2019) R: A language and environment for statistical computing. R Foundation for Statistical Computing, Vienna, Austria.

Ramos, M. O., \& Ribeiro, S. D. C. A. (2019). Compostagem orgânica do resíduo de caranguejo-uçá no cultivo de coentro. Revista Verde de Agroecologia e Desenvolvimento Sustentável, 14(2), 188-196.

RAO, R.C. (1952) Advanced statistical methods in biometric research. New York: John Wiley \& Sons, Inc. 390 pp.

Resende, F. V.; Souza, L. S. D.; Oliveira, P. S. R. D. \& Gualberto, R. (2005) Uso de cobertura morta na produção da cenoura em cultivo de verão. Ciênc. Agrotec. 29(1), 100-105.

Shapiro, S. S. \& Wilk, M. B. (1965). Analysis of variance test for normality. Biometrika, 1(1), 591-611.

Silva, V. D. P.; Sousa, I. F. D.; Tavares, A. L.; da Silva, T. G. F.; da Silva, B. B.; de Holanda, R. M.; Brito, J. I. B.; Braga, C.C.; de Souza, E.P. \& Silva, M. T. (2018). Evapotranspiration, crop coefficient and water use efficiency of coriander grown in tropical environment. Horticultura Brasileira, 36(4), 446-452.

Singh, D. (1981) The relative importance of characters affecting genetic divergence. The Indian Journal of Genetics and Plant Breeding, 41, $237-245$.

Souza, R. P.; Machado, E. C.; Silveira, J. A. G. \& Ribeiro, R.V. (2011) Fotossíntese e acúmulo de solutos em feijoeiro caupi submetido à salinidade. Pesquisa agropecuária brasileira, 46(6), 587-592.

Steel, R. G. D.; Torrie, J. H. \& Dickey, D. A. (1997) Principles and procedures of statistics: a biometrical approach. (3. ed.): Columbia. 666p.

Tavella, L. B.; Galvão, R. D. O.; Ferreira, R. L. F.; Neto,S. E. D. A. \& Negreiros, J. R. D. S. (2010). Cultivo orgânico de coentro em plantio direto utilizando cobertura viva e morta adubado com composto. Revista Ciência Agronômica, 41(4), 614-618.

Tobar-Tosse, D. E.; Castoldi, R.; Candido, W. D. S.; Ferraudo, A. S.; Charlo, H. C. D. O. \& Braz, L. T. (2015). Caracterização de genótipos de soja-hortaliça por análise de componentes principais. Ciência Rural, 45(7), 1214-1219.

Torres, S. B.; Dantas, A. H.; Pereira, M. F. S.; Benedito, C. P. \& Silva, F. H. A. D. (2012). Deterioração controlada em sementes de coentro. Revista Brasileira de Sementes, 34(2), 319-326.

Tunes, L. M.; Pedroso, D. C.; Barbieri, A. P. P.; Conceição, G. M.; Roething, E.; Muniz, M. F. B. \& Barros, A. C. S. A. (2011). Envelhecimento acelerado modificado para sementes de coentro (Coriandrum sativum L.) e sua correlação com outros testes de vigor. Revista Brasileira de Biociências, 9(1). 